\title{
Diagnosis of Intra-Abdominal Pressure in a Patient with Concomitant Injury as a Predictor of the Development of Acute Pancreatitis in the Post-traumatic Period: A Case Report
}

\author{
Alexei L. Charyshkin*, PhD, ScD; Roman M. Evseev; \\ Antonina V. Smolkina, PhD, ScD; A. V. Manokhin \\ Ulyanovsk State University \\ Ulyanovsk, the Russian Federation
}

\begin{abstract}
This article presents a clinical case of treatment of a patient with concomitant trauma. The increase in intra-abdominal pressure (IAP), as a predictor of the development of pancreatitis, was controlled by the developed method of radiation diagnostics. A method for assessing an increase in IAP, as a predictor of acute pancreatitis, is to quantify the volumetric blood flow in the superior mesenteric artery and superior mesenteric vein by Doppler ultrasound.(International Journal of Biomedicine. 2021;11(3):305-307.)
\end{abstract}

Key Words: acute pancreatitis $\bullet$ concomitant injury $\bullet$ intra-abdominal pressure $\bullet$ volumetric blood flow

For citation: Charyshkin AL, Evseev RM, Smolkina AV, Manokhin AV. Diagnosis of Intra-Abdominal Pressure in a Patient with Concomitant Injury as a Predictor of the Development of Acute Pancreatitis in the Post-traumatic Period: A Case Report. International Journal of Biomedicine. 2021;11(3):305-307. doi:10.21103/Article11(3)_CR1

\section{Abbreviations}

AP, acute pancreatitis; Hb, hemoglobin; IAP, intra-abdominal pressure; PRC, pancreatitis risk coefficient; RBC, red blood cells; SMA, superior mesenteric artery; SMV, superior mesenteric vein; WBC, white blood cells.

\section{Introduction}

In patients with concomitant injuries, one of the complications is acute pancreatitis (AP), which develops both with trauma to the pancreas itself and without mechanical impact on it, ${ }^{(1)}$ as a result of multiple organ failure. ${ }^{(2)}$ In the posttraumatic period, one of the pathogenetic mechanisms of the development of AP is an increase in IAP, and, consequently, a decrease in abdominal perfusion pressure, which leads to the development of microcirculatory insufficiency and ischemia in cases of impaired blood supply to the pancreas, which has been

*Corresponding author: Prof. Alexei L. Charyshkin, PhD, ScD. Head of the Faculty Surgery Department, Institute of Medicine, Ecology and Physical Education, Ulyanovsk State University. Ulyanovsk, the Russian Federation.E-mail: charyshkin@yandex.ru noted in $36 \%-47 \%$ of patients in intensive care units. Thus, as a precursor to the development of AP in patients with concomitant injuries, it is necessary to control the state of IAP. ${ }^{(3)}$

A method for assessing the risk of developing AP in patients with increased IAP

Ultrasound diagnostics of the SMA and SMV is performed to determine the dynamics of the maximum systolic blood flow velocity (Vmax), the minimum diastolic blood flow velocity (Vmin) (only in the artery) and the volumetric blood flow (Vvol). In the case of increasing the above indicators of the SMA and inversely proportional decreasing them in the SMV, the pancreatitis risk coefficient (PRC) ${ }^{(4)}$ is calculated by the formula:

$\mathrm{PRC}=$ Vvol SMA / Vvol SMV

Previously, this method was compared with the "Gold Standard" for determining IAP through the bladder. 
It is known that the following parameters are considered normal for the SMA: $V \max =1.27 \pm 0.24 \mathrm{~m} / \mathrm{s}, \mathrm{Vmin}=0.16 \pm 0.03$ $\mathrm{m} / \mathrm{s}$, and $\mathrm{Vvol}=791.82 \pm 48.47 \mathrm{ml} / \mathrm{min}$. For the SMV: Vmax $=0$ $.30 \pm 0.01 \mathrm{~m} / \mathrm{s}$ and Vvol IMV=553.62 $\pm 23.26 \mathrm{ml} / \mathrm{min} .{ }^{(5)}$

\section{Case Presentation}

A 47-year-old man was admitted on 05.26.2020 to the Ulyanovsk Regional Clinical Center for Specialized Types of Medical Care named after V.I. EAT. Chuchkalov. Admitting diagnosis: Concomitant injuries. Closed spinal cord injury Contusion of the lumbar spinal cord. Closed unstable compression comminuted fracture of the body and arches of the L1 vertebra, grade 3. Closed compression fracture of the ThVI vertebral body, grade 1. Fracture of the spinous process of the ThV, ThVI vertebrae, the transverse process of the LIII vertebra on the left. Closed abdominal trauma. Rupture of the small intestine, mesentery of the small intestine. Hematomas of the mesentery of the small intestine. Hemoperitoneum. Contusions of soft tissues of the trunk, limbs. Traumatic shock, stage 3.

The man was injured as a result of a fall from a height. Complaints: pain in the lumbar spine, decreased sensitivity and motor activity in the lower extremities, lack of independent urination.

\section{Clinical Findings and Diagnostic Assessment}

Neurological status: clear consciousness, Glasgow Coma Scale - 14 points. Tendon reflexes $\mathrm{D}=\mathrm{S}$, from the legs were sharply reduced. Rough inferior paraparesis. Dysfunction of the pelvic organs by the type of urinary retention. There were no meningeal symptoms.

CBC: $\mathrm{RBC}-4.18 \times 10^{12} / \mathrm{L}, \mathrm{Hb}-144 \mathrm{~g} / \mathrm{l}$, Hct $-40.2 \%$, WBC - $6.3 \times 10^{9} / \mathrm{L}$, eosinophils- $2 \%$, stab neutrophils - $6 \%$, segmented neutrophils - 65\%, Lymphocytes- $18 \%$, monocytes $-9 \%$, ESR - $20 \mathrm{~mm} / \mathrm{hr}$.

Blood chemistry test $(05.26 .2020)$ : total protein $-76 \mathrm{~g} / 1$, ALT- 65.4 U/L, AST-36.6 U/L, urea - $4.3 \mathrm{mmol} / \mathrm{L}$, creatinine - $55.7 \mathrm{mmol} / \mathrm{L}$, bilirubin - $6.5 \mathrm{mmol} / \mathrm{L}$, amylase - $43 \mathrm{U} / \mathrm{L}$, glucose- $5.1 \mathrm{mmol} / \mathrm{L}$.

General urine analysis $(05.30 .2020)$ : Normal values

CT scan of the brain and cervical spine (05.26.2020): No focal or bone-traumatic pathology was revealed. The midline structures of the brain were not displaced.

CT scan of the chest, abdomen, spine, and pelvis (05.26.2020): Closed unstable compression comminuted fracture of the body and arches of the L1 vertebra, grade 3. Closed compression fracture of the ThVI vertebral body, grade 1. Fracture of the spinous process of the ThV, ThVI vertebrae, the transverse process of the LIII vertebra on the left. There was blood in the abdominal cavity on the left.

$\underline{\text { IAP }}(05.26 .2020)-16 \mathrm{mmHg}$.

Ultrasound of the pancreas $(05.26 .2020)$ : The pancreas was of a typical shape and location; the contours were clear and even. Head - $32 \mathrm{~mm}$, body $-18 \mathrm{~mm}$, tail $-30 \mathrm{~mm}$. Echotexture was homogeneous and isoechoic. Wirsung's duct was not widened. SMA: Vmax $-1.36 \mathrm{~m} / \mathrm{s}$, Vmin $-0.18 \mathrm{~m} / \mathrm{s}$, and Vvol $827.39 \mathrm{ml} / \mathrm{min}$; SMV: Vmax - $0.28 \mathrm{~m} / \mathrm{s}$, Vvol - $568.2 \mathrm{ml} / \mathrm{min}$ $\underline{\mathrm{PRC}}=1.456$.

Blood amylase $(05.26 .2020)-96 \mathrm{U} / \mathrm{L}$
$\operatorname{IAP}(05 / 28 / 2020)-22 \mathrm{mmHg}$.

Ultrasound of the pancreas $(05 / 28 / 2020)$ : The pancreas was of a typical shape and location; the contours were unclear. Head - $35 \mathrm{~mm}$, body - $21 \mathrm{~mm}$, tail - $35 \mathrm{~mm}$. Homogeneous echotexture, hyperechoic areas. Wirsung's duct was not widened. SMA: Vmax - $1.46 \mathrm{~m} / \mathrm{s}$, Vmin $-0.19 \mathrm{~m} / \mathrm{s}$, and Vvol $891.35 \mathrm{ml} / \mathrm{min}$. SMV: Vmax - $0.4 \mathrm{~m} / \mathrm{s}$, Vvol - $483.63 \mathrm{ml} / \mathrm{min}$

$\mathrm{PRC}=1.843$. Blood amylase $(05 / 28 / 2020)-98 \mathrm{U} / \mathrm{L}$

IAP $(06.01 .2020)-25 \mathrm{mmHg}$.

Ultrasound of the pancreas (06.01.2020): The pancreas was of a typical shape and location; the contours were unclear. Head - $35 \mathrm{~mm}$, body $-21 \mathrm{~mm}$, tail $-35 \mathrm{~mm}$. Homogeneous echotexture, hyperechoic areas. Wirsung's duct was not widened.

SMA: Vmax $-1.74 \mathrm{~m} / \mathrm{s}, \mathrm{Vmin}-0.21 \mathrm{~m} / \mathrm{s}$, and Vvol $1008.72 \mathrm{ml} / \mathrm{min}$; SMV: Vmax - $0.24 \mathrm{~m} / \mathrm{s}$, Vvol - $349.63 \mathrm{ml} / \mathrm{min}$

$\underline{\mathrm{PRC}}=2.885$. Blood amylase $(06.01 .2020)-96 \mathrm{U} / \mathrm{L}$.

IAP $(06.03 .2020)-26 \mathrm{mmHg}$.

Ultrasound of the pancreas (06.03.2020): The pancreas was of a typical shape and location; the contours were uneven, unclear. Head - $39 \mathrm{~mm}$, body - $25 \mathrm{~mm}$, tail -38 $\mathrm{mm}$. Heterogeneous echotexture, areas of hyperechoicity. Wirsung's duct was expanded up to $4 \mathrm{~mm}$. SMA: Vmax -2.38 $\mathrm{m} / \mathrm{s}, \mathrm{Vmin} 0.23 \mathrm{~m} / \mathrm{s}$, and Vvol $-1609.01 \mathrm{ml} / \mathrm{min}$. SMV: Vmax - $0.22 \mathrm{~m} / \mathrm{s}$, Vvol - $331.27 \mathrm{ml} / \mathrm{min}$ (Figure 1).

$\underline{\mathrm{PRC}}=4.857$. Blood amylase $(06.03 .2020)-148 \mathrm{U} / \mathrm{L}$

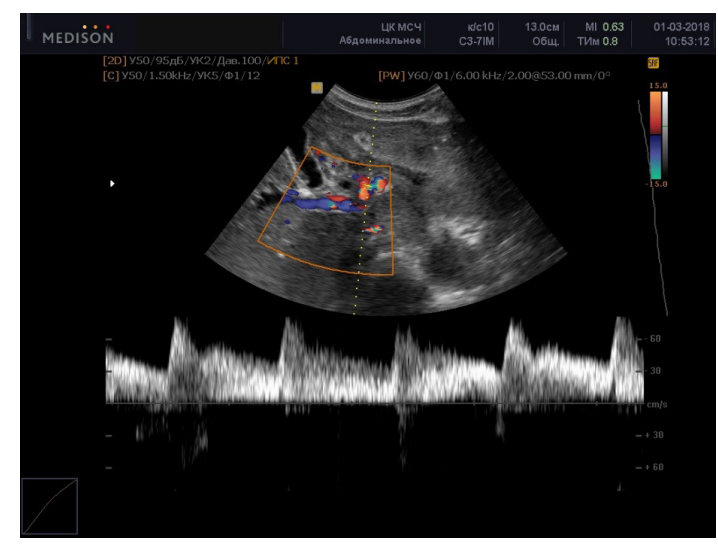

Fig. 1. Ultrasound of the SMV in the color duplex scanning mode (06.03.2020)

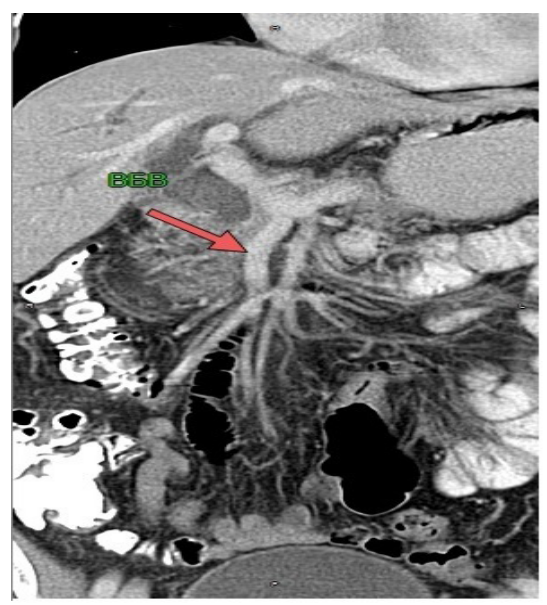

Fig. 2. CT scan of the abdominal organs with $3 D$ reconstructions. 
On Day 7 after admission, the patient was diagnosed with signs of AP. Starting from 06.01.2020, PRC $>2$. To control the data obtained, CT (03.06. 2020) of the abdominal organs with 3D reconstructions was performed (Figure 2). Expansion of the SMV was clearly visible. The patient was prescribed a standard treatment regimen for AP. Due to the timely diagnosis of intra-abdominal pressure and correction of therapy, the patient was discharged in satisfactory condition on Day 21 of treatment.

\section{Competing Interests} interests.

The authors declare that they have no competing

\section{References}

1. Alekseechkina OA., Dubrov EYa, Kosolapov DA, Abuchina VM. [Ultrasound diagnostics of traumatic pancreatitis in concomitant trauma]. Russian Journal of Gastroenterology, Hepatology, Coloproctology. 2014;(2):3135. [Article in Russian].

2. Bellam BL, Samanta J, Gupta P, Kumar M P, Sharma V, Dhaka N, Sarma P, Muktesh G, Gupta V, Sinha SK, Kochhar R. Predictors of outcome of percutaneous catheter drainage in patients with acute pancreatitis having acute fluid collection and development of a predictive model. Pancreatology. 2019 Jul;19(5):658-664. doi: 10.1016/j.pan.2019.05.467.

3. Aliyev SA, Aliyev ES. [Intraabdominal hypertension and abdominal compartment syndrome: criteria for the definition of terminology and classification, pathophysiological and surgical aspects of the problem]. Herald of Surgical Gastroenterology. 2018;(2):3-10. [Article in Russian].

4. Evseev RM, Smolkina AV, Zaitsev AV. A method for assessing the risk of developing acute pancreatitis in patients with increased intra-abdominal pressure. RF patent No. 2703816; 2019. Patent holder R.M. Evseev. [In Russian].

5. Belsky II. The role of intra-abdominal pressure in the diagnosis and treatment of acute pancreatitis. Abstract of $\mathrm{PhD}$ Thesis. St. Petersburg; 2016. [In Russian]. 